\title{
Chronic non-communicable diseases, risk and health promotion: social construction of Vigitel participants
}

Erika de Azevedo Leitão Mássimo ${ }^{1}$

Hercília Najara Ferreira de Souza ${ }^{2}$

Maria Imaculada de Fátima Freitas ${ }^{2}$

${ }^{1}$ Departamento de Enfermagem, Pontifícia Universidade Católica de Minas Gerais. Av. Dom José Gaspar 500, Coração Eucarístico. 30535-901 Belo Horizonte MG Brasil. erikazevedo@pucminas.br ${ }^{2}$ Escola de Enfermagem, Universidade Federal de Minas Gerais.

\begin{abstract}
The dimension of choice and adherence to healthy lifestyles is in the area of social constructions made in representations of individuals and had not yet been included in the Surveillance of Risk and Protective Factors for Chronic Diseases by Telephone Survey (VIGITEL) analysis systems. This article aims to understand, in individual narratives, representations contained in the trajectories of people's lives selected from the 2010 VIGITEL sample, in Belo Horizonte, Minas Gerais. It is a qualitative study based on Social Representation Theory. Thirty in-depth and open interviews with subjects selected from the 2010 VIGITEL sample were conducted in Belo Horizonte in the State of Minas Gerais. The Structural Analysis of Narrative technique was used to reveal the content of speeches. Age and heredity representations related to NCDs are part of the spectrum of current scientific information. Learning from childhood onwards is the basis of care. The lack of comprehension of the pathophysiology of NCDs, and the depth of representations of illness and death related to communicable diseases, is partly responsible for the difficulty of preventing NCDs.

Key words Risk, Health promotion, Chronic disease, Public health
\end{abstract}




\section{Introduction}

Preventive interventions for chronic non- communicable diseases (CNCD) and strategies to change lifestyles in the general population aim to reduce the prevalence of those diseases in Brazil and worldwide ${ }^{1}$.

Brazil is undergoing an epidemiological and demographic transition with a decrease in deaths from infectious diseases and an increase in deaths from chronic non-communicable diseases, similar to the global epidemiological scenario. Current data show that $72 \%$ of deaths from known causes result from CNCD in Brazil'.

Clinical and epidemiological studies have enabled the identification of various risk factors that determine the health status of individuals and, specifically, the onset of diseases resulting from those conditions ${ }^{2}$.Two specific groups were identified among the risk factors. The first includes factors considered non-modifiable: gender, age, and family history. The second group includes behavioral factors: smoking, inadequate nutrition, sedentary lifestyle, and alcohol consumption ${ }^{3}$.

Behavioral risk factors are enhanced by socioeconomic, cultural, and environmental conditions, which are supported by the contemporary context of competitiveness and individualism, wherein 'having' has surpassed 'being' in a way that is culturally accepted by society". The economic, political, social, and cultural transformations contribute to modify how individuals and communities organize their lives and choose specific lifestyles. Such transformations facilitate or complicate people's access to more health-promoting living conditions and directly affect disease patterns $\mathrm{s}^{3,5,6}$.

The Telephone-Based Surveillance of Risk and Protective Factors for Chronic Diseases (Vigilância de Fatores de Risco e Proteção para Doenças Crônicas por Inquérito Telefônico, Vigitel) system was implemented in 2006 to monitor risk and protective factors for CNCD in 27 Brazilian state capitals, which improved the quality of epidemiological information. However, subjective aspects regarding individual and collective healthy lifestyle and habits, from the perspective of the subjects themselves, were not included in the data and in studies based on said data.

For that purpose, it was necessary to include new methods for understanding the dimension of choice and adherence to healthy lifestyles, based on what is socially constructed and valued by individuals and society within their specific social contexts. Therefore, this paper is a discussion of representational forms of prevention to ward a better quality of life, of risk perception, and of health protection, considering individual autonomy as well as access to goods and social rights.

Subjectivity, knowledge, and representations that are constructed and explained in social interactions provide the individual's background, which includes practices to promote health and to prevent and control chronic non-communicable diseases.

Brazil exhibits health inequalities, especially regarding health promotion, and refractory representations prioritizing medical care, focused on doctor visits and the use of medication, are still observed despite the existence of somewhat widespread health information ${ }^{7-10}$.

Information, per se, does not modify healthcare practices ${ }^{7,11}$. Thus, individuals take risks, more or less consciously, which result in difficulties in adhering to healthy lifestyles. Given that the individuals' life contexts are where representations are created and transformed, the understanding of representations of health and disease, $\mathrm{CNCD}$, and the risks of disease and death may account for the difficulties and opportunities in adhering to healthy lifestyles.

This study aimed to understand, using individual narratives, representations that are part of the life trajectories of people selected from the sample of Vigitel 2010 in Belo Horizonte, Minas Gerais, examining their lifestyle and healthcare habits, including health risk, health promotion, and the prevention ofCNCD.

\section{Methods}

\section{Type of Study [}

This work is a qualitative research study, using the critical version of the Social Representations Theory by Giami and Veil as the theoretical framework ${ }^{12}$. According to those authors, representations are a "social and psychological activity consisting of constructing an object by associating with it external awareness elements and elements linked to individual fantasies, regarding the position occupied relative to the object". This description expresses representations as the individuals' singular and simultaneously universal reflections, decisions, and actions because they are partly defined by their social 'learning'. Representations are considered as 'viewpoints' 
or 'value judgments' on objects, introjected and questioned throughout life by the subjects in a constantly changing process built through social interactions.

Thus, all representations are social representations because, according to Giami and Veil' "'their contents derive from materials present in contemporary and past socio culture, functioning as the imaginary"12,13, "without separation between individual and collective expressions and meanings of representations, but rather homology, which translates into an approach that considers the social to be contained and observable in individual speech..."12.

Qualitative studies are a key tool for designing health policies by making it possible to understand the ways that individuals and social groups think and act when facing diseases and their underlying issues. However, such studies are, as a rule, not aimed at acquiring knowledge that may be generalized and universalized but rather at deepening the understanding of the particularities and peculiarities of the social experience of individuals ${ }^{14}$.

\section{Population and Sample}

The city of Belo Horizonte, one of the capitals of the survey, was chosen as the site to address and analyze in detail issues related to the subjectivity of individuals. That choice was made considering the magnitude of CNCD in the Southeast region of Brazil, the need to further develop the objective assessments conducted, and the fact that completeness and data saturation, rather than numerical or spatial representativeness, are the criteria adopted for in-depth interviews ${ }^{15-17}$.

The study population included individuals interviewed in the Vigitel 2010 in Belo Horizonte, Minas Gerais. The 2,000 study subjects, selected from existing phonebooks based on their phone numbers, were divided into lists according to gender and age group $(1-$ from 18 to 30 years; 2- from 31 to 50 years; and 3- 51 years or older), thus totaling six lists.

The age group division was based on the assumption that the construction of representations occurs throughout $\operatorname{life}^{18}$ and on the existence of common social and cultural characteristics shared among individuals in the same age group, without overlooking possible inferences from gender or economic differences that might exist between participants.

The names of study subjects were numbered in ascending order per list, after organizing them according to gender and age group in the lists. Thirty subjects were randomly selected from each list by drawing lots. The selected individuals were invited to participate in the study until 10 subjects (including 5 men and 5 women)per age group agreed to participate. Thus, the initial group of interviewees consisted of 30 people, although new draws could occur if necessary until reaching data saturation for each age group ${ }^{19}$.

The preliminary analysis of the 30 interviews conducted showed the occurrence of data saturation because there was repeatability, consistency, and sufficiency of information for analysis of the proposed object. Therefore, the data collection process was ended with this number of interviews.

\section{Data Collection and Analysis}

In-depth, open-ended individual interviews were conducted by the researchers in the period from November2011 to January 2012at the Nursing School of the Federal University of Minas Gerais (Universidade Federal de Minas Gerais - UFMG) and at home at a pre-scheduled time, according to the availability of subjects. After the subjects freely signed the informed consent form, the interviews were audio recorded and fully transcribed for data analysis. The ethical guidelines defined in Resolution 196/1996 of the National Health Council (Conselho Nacional de Saúde) were fully met ${ }^{20}$.

The method of Structural Analysis of Narrative (SAN), proposed by Demazière and Dubar ${ }^{21}$ and advocated by Barthes et al. ${ }^{22}$, was used to analyze the interviews. Barthes et al. ${ }^{22}$ argue that everything in a narrative has meaning, and therefore.

Understanding a narrative is not merely to follow the unfolding of the story it is also to recognize its construction into 'storeys', to project the horizontal concatenations of the narrative 'thread' onto an implicitly vertical axis; to read (to listen to) a narrative is not merely to move from one word to the next, it is also to move from one level to the next. Similarly, the "search" carried out over a horizontal set of narrative relations may well be as thorough as possible but must still, to be effective, also operate "vertically": meaning is not 'at the end' of the narrative, it runs across it.

Therefore, the Structural Analysis of Narrative values the web of argumentative construction of subjects and not only illustrations or parts considered relevant to the object in question. Subjects are interpreting the world when narrat- 
ing, explaining consistencies and contradictions when presenting their viewpoints on the objects. Therefore, everything is important in narration, as it expresses the subjectivity in the analysis.

The method of analysis proposed by the authors is defined by 'deconstructing' the interview into numbered concatenations, wherein facts, their explanations, and the characters involved are identified. These concatenations were given a title that preliminarily specified the central object of each concatenation. The interview was then 'reconstructed' by clustering concatenations addressing the same object and unveiling speech conjunctions and disjunctions. The representations of the objects of interest ${ }^{21}$ are found in this stage, which confirmed that they were constructed and reconstructed throughout the life path of the subject. Thus, SAN allowed the definition of timelines using the representations found in each of the 30 interviews. A diagram including the life path of respondents was drawn for each timeline, with their viewpoints, value judgments and respective contexts, which change throughout life. The cross-sectional analysis of the set of interviews was performed by clustering the concatenations specifying the subjects' reflections, which made it possible to interpret the construction of representations on health and disease, CNCD risks and prevention, and groups both according to age group and in its entirety. The clusters were then named based on the researchers' interpretation, forming categories that were ultimately further developed through their theorization.

This study is included in the project "Study of risk and protective factors and healthcare system for chronic diseases in the municipality of Belo Horizonte, Minas Gerais,"approved by the Research Ethics Committee of the Federal University of Minas Gerais (Comitê de Ética em Pesquisa da Universidade Federal de Minas Gerais), as a Vigitel subproject, within the encompassing Vigitel project.

\section{Results}

Data interpretation defined encompassing categories related to CNCD: Healthcare and Health Promotion; Health and Disease and Risk.

The consolidation of the subjects' social and subjective constructions regarding the objects of CNCD-related health promotion and risk was reached based on this synthesis, the narrowing of representations in each category, and comparison with the literature. Said consolidation allowed the generation of theoretical categories, which will be discussed in this article: 1) health promotion: a still distant practice, and 2) the culture of age based on ways of dealing with health and disease.

1) Health promotion: a still distant practice

Adherence to healthy lifestyles and a propensity for care and self-care are social constructs acquired throughout life. The results show that the people most adherent to the health promotion concept experienced it from an early age, i.e., they learned to take care of themselves and to adopt healthy habits, which was introjected as a value judgment early in their lives.

The analysis of life paths showed that learning since childhood is the foundation of healthcare. The most important or deepest representations, which will define the lifestyle and health promotion, are introjected and constructed beginning in childhood. Although other representations may arise throughout life, the foundational representation remains.

The subjects' discourses show the representation of food as the center of health promotion, which is an object wherein the formation of representations is more relevant. The value that will be assigned to health promotion is based on childhood experiences, particularly what was lived through and heard from the mother figure.

Another noteworthy finding regards the fact that health promotion occurs at different levels and in a different way depending on the subjects' age group. In each age group, subjects promote health according to their experiences: that is, the subjects' experiences throughout life presumably change the representations, and thus, they modulate the different ways of life and health promotion in each age group. However, the deepest representations remain and will define the increased capacity of subjects for making healthy decisions in their lives.

The study of representations indicated that subjects think and therefore promote health differently in each age group. Younger subjects(from 18 to 30years)identified the importance of maintaining a healthy diet, even when they failed to adhere to one, and the practice of physical activity as healthcare, albeit more focused on aesthetic purposes than on the prevention of CNCD. The subjects from age group 2 (from 31 to 50 years) indicated diet as the most important consideration to prevent $\mathrm{CNCD}$, although they considered this preventive diet difficult "because it precludes a normal social life". The central repre- 
sentation that organizes the reasoning of subjects from that age group is that 'becoming an adult is to live contradictions in a more or less conscious manner'. Individuals older than 51years of age (age group 3) attach more importance to the act of modifying lifestyle habits to prevent or control diseases.

The predominance of the culture of prescriptive medicine was recurrently found in the subjects' reports. For them, healthcare is visiting the physician and conducting exams regularly. That representation clearly contradicts the health promotion-related notions of autonomy and empowerment.

Accordingly, the study results show that representations of healthcare define such demands as a figure of imagination expressed in the ways the subjects live and relate to other people and to healthcare professionals and services.

\section{2) The age culture based on ways}

\section{of dealing with health and disease}

Health promotion in each age group is modulated by the representations of age and heredity related to CNCD. The central representation of CNCD is related to age. Thus, young people believe that the risks of getting sick are higher for the elderly and are not an immediate concern for their age group. The subjects from the other age groups also consider CNCD to be related to age. However, they are beginning to worry about the possibility of its occurrence because they are already close to an age group they consider 'at risk'. Chronic diseases are actually more frequent in people over 50 years, as mentioned by the subjects of this age group who participated in the survey, who believe they are at greater risk of illness and death by CNCD.

Overcoming the original representation of age-related CNCD is essential to recognizing the need to adopt healthy lifestyle habits early in life. The representation of CNCD as hereditary is also present in the interviewees' statements. However, they fail to change their lifestyle and healthcare habits, especially young people, despite recognizing the hereditary nature of CNCD, thus failing to adopt healthy habits because they believe they have not yet reached the age of onset (older than 40 years) of those diseases.

The relationship between CNCD and age is a stronger representation than the representation of its hereditary nature, and the former modulates the subjects' habits regarding prevention and healthcare more intensely.
The representation of age-related CNCD follows the subjects' life path, affecting the adoption of healthy habits, and corroborates the representation that individuals from different age groups promote health differently. Therefore, the concern with and the ability to care for oneself will evolve and improve with age.

Although information on CNCD is widely available to the population, that information, based on biomedical or epidemiological risk, seems to fail to generate and stimulate healthy self-care habits, as if the epidemiological risk were 'external to the subject', as something present in the world and thus nota risk introjected or constructed by them.

A key discovery emerged from the finding that interviewees mix representations of risk for CNCD with their representations of risks for communicable diseases. Several of the statements made during the interviews have shown the miasmatic and disease transmissibility view permeating the representation of an aseptic world as a healthy world or free from the danger of disease, despite the fact that the focus on CNCD as our object of study was maintained throughout the whole interview.

That finding enables hypothesizing that misunderstanding the pathophysiological processes of CNCD and the lack of a causative agent or a culprit microorganism hinder the prevention of this group of diseases because the subjects' deepest representations related to disease and death are representations of communicable diseases.

\section{Discussion}

\section{Health promotion: a still distant practice}

Although the interactions between subjects lead to the emergence of other representations throughout life, the basis of the representation remains. Once the nucleus of the representation is consolidated, that central representation, termed 'original representation' by Giami and Veil' ${ }^{12}$, will serve as a filter to accept or reject the new representations, which will be peripheral representations despite being social constructions of temporality.

The focus on food as the center of health promotion emerged from the content of the subjects' statements. According to Rotenberg and De Vargas $^{23}$, dietary practices derive from knowledge and experiences constructed from the living con- 
ditions, culture, social networks, and scientific knowledge of each historical and cultural period. The authors analyzed dietary practices, ranging from breastfeeding to everyday family meals, and determined that eating habits and dietary practices are permeated by maternal knowledge, which begins in childhood, and are associated with urban consumption habits. In this context, one should highlight the value assigned to representations experienced with the mother figure since childhood.

Everything allowed or prohibited in dietary practices is a language of social classification of food because food symbolizes the daily contact with life, not only in the context of organic need but also, especially, in the sense of social participation in the world ${ }^{24}$.

$\operatorname{Giard}^{25}$ notes that people eat what is available and what they like to eat. The "power" considers availability based on food production, distribution and trade; considers accessibility, such as price; and considers what is allowed by culture and what is valued by social organization. According to the author, taste is complex and is associated with the game of attractions and repulsions, grounded in childhood habits, based on what is available and on how the food is provided.

Since 1999, several world health agencies, including the Heart and Stroke Foundation of Canada (HSFC), have shown that lifestyles increase the risk of chronic diseases, which has been corroborated by other studies ${ }^{1,26}$. Although pathophysiological alterations related to CNCD are, in principle, asymptomatic, they begin early in life, and therefore, CNCD prevention must be conducted beginning in childhood. There is strong evidence of success in preventing CNCD with pro-healthy nutrition intervention in school environments $\mathrm{s}^{26,27}$.

The objectives of reducing obesity prevalence in children and adolescents are among the national goals set forth in the plan for dealing with $\mathrm{CNCD}^{1}$. Reaching those goals will involve more healthcare agents and resources than services and media campaigns, as shown by the data. Coordination of family, child and school becomes necessary for this purpose to ensure that representations learned within families may still be reconstructed within them, through contradictions experienced in various environments and social relationships. Therefore, co-responsibility and co-management actions to be implemented in the process of the growth and development of children must be considered.
Health promotion involves choices and therefore does not lie in the realm of scientific knowledge but rather in the realm of values and is linked to processes that are not expressed in a precise manner and are not readily measurable ${ }^{28}$.

The results show that subjects think and promote health differently in the three age groups analyzed. Therefore, the subjects' viewpoints must be considered, according to age group, to think about health promotion differently. This difference may contribute to choices that are both healthy and consistent with the subjects' value judgments at each period of their lives.

However, subjectivity, health, and disease experiences from the subjects' viewpoint and how to address those issues are uncharted territory ${ }^{29}$. According to the author, the history of patients' perspectives is as underdeveloped now as it was in the mid-1980s, when the patients' history could apparently become a new paradigm to rewrite the history of medicine.

Buss $^{30}$ considers that health promotion seeks to coordinate health issues with living conditions and quality of life issues, stating that this ideology is a promising strategy for dealing with the multiple health problems affecting people and their surroundings. The findings of this study clarify that living conditions and quality of life may not be evaluated merely as objective and measurable data but should include the ways of thinking about life and the subjective rationality of individuals. The ability to promote health is a strategy associated with values that change throughout life, including the quality of life, health, solidarity, equity, democracy, citizenship, development, and social participation, as stated by the cited author.

Another key issue is that actions based on a fragmented view of healthcare and the people receiving care still predominate, despite efforts conducted to implement a new healthcare model, specifically through the reorganization of primary care by means of the Family Health Strategy (Estratégia Saúde da Família, ESF). Therefore, "that reductionist and fragmented view of reality must be overcome toward a comprehensive notion of the health-disease process, the people involved in that process, and the organization of Healthcare Services"31.

By increasingly demanding medical consultations, people are transformed into excessively voracious consumers of more specialized technologies and not of care itself, rendering them dependent. This dependence decreases their autonomy and ability to act on their lives and on 
the environment to maintain, recover, or increase health and freedom, which are regarded as the coefficient of experienced freedom and the ability to establish vital standards ${ }^{32}$. We live in the time of the 'medical culture' outlined by the 'image of the physician' - the search for and the power of healing, which expresses the feeling of credibility and faith in medicine that the population holds ${ }^{31}$.

In a social universe undergoing a loss of values, the medical culture - which has become a key element of our culture - "seeks to assign a meaning: the medical meaning, which consists in living utopically to fully avoid disease, delay the time of death, or even preclude it, in short, to preserve the most precious of all goods at any price: health" 33

Perhaps the medical culture results from the inheritance of a medicalized concept of health, given the demand for drugs and exams as if they would alone solve the users' demands ${ }^{31}$, which is the "the imaginary production of demand" that results in the high pursuit of medical action, according to Merhy and Franco ${ }^{34}$. The authors "assume that this demand is socially constructed and related to the profile of Healthcare Services and how the production of care and the relationships between healthcare professionals and the people they serve are processed".

Thus, the population should participate in other services provided in addition to medical appointments, and the user's link to the healthcare service is essential for that purpose. The establishment of such a link enables advances toward the much-desired 'demedicalization' and toward clinical expansion through health education, healthy lifestyle practices, interdisciplinary care and support networks for the social construction of healthcare ${ }^{35}$.

The findings of this study show that representations are in agreement with the centered and hospital-centric medical model that we seek to overcome, which is the antithesis of health promotion, maintaining a close relationship with the fragmentation of healthcare processes and the model focused on acute health conditions.

According to Verdi and Caponi ${ }^{36}$ and to Carvalho and Gastaldo ${ }^{37}$, in the last decade, health promotion has become one of the most cited and recurring topics in different fields of knowledge production and health practices. Health promotion is understood as a health model characterized by a set of theoretical, cultural, and technical elements organized toward meeting the demands of the health sector and whose existence is only enabled in actual reality ${ }^{36}$. The findings of this study indicate that we are far from achieving this goal in our current health practices.

The results found herein show that the interviewees' imagination is still permeated by everyday actions supporting healthcare representations restricted to visiting the physician and performing exams.

\section{The culture of age based on ways of dealing with health and disease}

The literature has shown a trend toward earlier onset of $\mathrm{CNCD}$, and theWHO${ }^{26}$ data have shown that approximately $1 / 4$ of CNCD-related deaths worldwide affect individuals younger than 60 years of age.

The fear of disease based on the horror arising from old epidemic diseases is a persistent representation, regardless of scientific knowledge and information circulating in the media or available in healthcare services ${ }^{38}$.

Contagion is a primitive experience regarding the fear of contact with others. The panic experienced during epidemics was related to obscurantist and irrational attitudes of rejection. They are the so-called 'original' representations, thus termed by Giami and Veil ${ }^{12}$, that perpetuate in people's minds, hindering the understanding of other types of diseases, specifically diseases caused by the lifestyles and behaviors adopted.

Therefore, public policies must consider and reflect on the representations found for overcoming them by increasing the amount and quality of CNCD-related information and by empowering and holding the individuals accountable. This approach will allow individuals to understand that health promotion and the adoption of healthy lifestyles, regarding chronic conditions, are to CNCD what etiologic agents are to communicable diseases.

Oliveira and Egry ${ }^{39}$ consider the need to overcome those theories and the classical causal models centered on individual actions by adopting interactive models incorporating both individual and collective actions. A new way to think of health and disease should, according to the authors, include explanations for the universal findings that mortality and morbidity follow a gradient that crosses socioeconomic classes, such that lower income or social status is associated with a worse health condition. 


\section{Final considerations}

The interpretation of the results revealed that representations are contained in the interviewees' life paths and enabled an understanding of their healthcare practices and lifestyles as well as health promotion and CNCD prevention behaviors.

The finding that "learning since childhood is the foundation of care" emerges as a key guiding instrument for public health policies because policies may focus on hygiene and health promotion actions that reach the child population as well as on routine healthcare actions.

Furthermore, healthcare education programs must incorporate health promotion, thus replacing an idealistic or prescriptive discourse with one that includes the representations of the future healthcare professionals themselves and that develops knowledge that incisively incorporates the understanding that customers and users of the healthcare system hold representations that do not necessarily correspond to what scientific objectivity regards as standard. This goal requires willingness from future healthcare professionals to take active stances and abandon the prescription approach for a new approach based on interactions, and it also requires them to have good listening skills to understand the representations of subjects and their own, which would positively affect the new construction of healthcare. Thus, education programs in the health field must offer interdisciplinary experiences of care and health education, not electively but as a paradigm shift in vocational training.

The results of this study, in addition to furthering knowledge, will hopefully contribute to designing operational strategies to address $\mathrm{CNCD}$, thus enabling managers to develop health actions based on co-responsibility networks between individuals and communities by advocating and promoting improved living conditions and population health. 


\section{Collaborations}

EAL Mássimo and MIF Freitas worked on the research, conception, experimental design, analysis, data interpretation and writing of the article. HNF Souza worked on the research, formatting and critical revision of the article.

\section{Acknowledgments}

To the Department of Health/National Health Fund - Vigitel Project (Ministério da Saúde/ Fundo Nacional de Saúde - Projeto Vigitel)for funding the research studyandMinas Gerais State Research Foundation (Fundação de Amparo a Pesquisa do Estado de Minas Gerais, FAPEMIG) Minas Gerais Researcher (Pesquisador Mineiro).

\section{References}

1. Brasil. Ministério da Saúde (MS). Secretaria de Vigilância em Saúde. Departamento de Análise de Situação de Saúde. Plano de ações estratégicas para o enfrentamento das doenças crônicas não transmissíveis (DCNT) no Brasil 2011-2022. Brasília: MS; 2011. (Série B. Textos Básicos de Saúde)

2. Santos AC. Changing epidemics. Arquivos de Medicina 2006; 20(3):75-77.

3. Malta DC, Cezario AC, Moura L, Moraes Neto OL, Silva Junior JB. A construção da vigilância e prevenção das doenças crônicas não transmissíveis no contexto do Sistema Único de Saúde. Epidemiologia e Serviços de Saúde 2006; 15(3):47-65.

4. Homem ML. Entre próteses e prozacs: O sujeito contemporâneo imerso na descartabilidade da sociedade de consumo. In: Estados Gerais da Psicanálise: Segundo Encontro Mundial, Rio de Janeiro. 2003.

5. Brasil. Ministério da Saúde (MS). Secretaria de Vigilância à Saúde. Secretaria de Atenção à Saúde. Diretrizes e recomendações para o cuidado integral de doenças crônicas não-transmissíveis. Brasília: MS; 2008.

6. World Health Organization (WHO). Preventing chronic diseases a vital investments. Geneva: WHO; 2005.

7. Lefevre F, Lefèvre AMC. Saúde, Empoderamento e Triangulação. Saúde Soc 2004; 13(2):32-38.

8. Patussi MP, Moyses SJ, Junges JR, Sheiham A. Capital Social e a agenda de pesquisa em epidemiologia. Cad Saude Publica 2006; 22(8):1525-1546.

9. Santos WG. O paradoxo de Rousseau: uma interpretação democrática da vontade geral. Rio de Janeiro: Rocco; 2007.

10. Ayres JRCM. Organização das ações de atenção à saúde: modelos e práticas. Saúde Soc 2009; 18(Supl. 2):11-23.

11. Ayres JRCM. Epidemiologia, promoção da saúde e o paradoxo do risco. Revista Brasileira de Epidemiologia 2002; 5(Supl. 1):28-42.

12. Giami A, Veil C. Enfermeiras frente a Aids: representações e condutas, permanências e mudanças. Canoas: Ulbra; 1997.

13. Giami A. Representações e sexualidade: psicologia social e pluridisciplinaridade. In: Loyola MA, organizador. A sexualidade nas Ciências Humanas. Rio de Janeiro: EDUERJ; 1998. p. 201-225.

14. Freitas MIF. A gestão do segredo na vida de casais diante da soropositividade pelo HIV. Belo Horizonte: EEUFMG, MS, Cooperacão Técnica Sida Brasil/França; 1998. (Publicação de Relatório Técnico - Divulgação Científica).

15. Brasil. Ministério da Saúde (MS). Secretaria de Atenção à Saúde. Departamento de Atenção Básica. Vigilância em Saúde. 2a ed. rev. Brasília: MS; 2008. (Normas e Manuais Técnicos - Cadernos de Atenção Básica, n. 21).

16. Brasil. Ministério da Saúde (MS). Saúde Brasil 2009: Uma análise da situação de saúde e da agenda nacional e internacional de prioridades em saúde. Brasília: MS; 2010.

17. Brasil. Ministério da Saúde (MS). Secretaria de Vigilância em Saúde. Secretaria de Gestão Estratégica e Participativa. Vigitel Brasil 2010: vigilância de fatores de risco e proteção para doenças crônicas por inquérito telefônico. Brasília: MS; 2011.

18. Mássimo EAL, Freitas MIF. Riscos para doenças crônicas não transmissíveis, na ótica de participantes do Vigitel. Saúde e sociedade 2014; 23(2):651-663. 
19. Pope C, Mays N, organizadores. Pesquisa qualitativa na atenção à saúde. $3^{\mathrm{a}}$ ed. Porto Alegre: Artmed; 2008.

20. Brasil. Ministério da Saúde (MS). Conselho Nacional de Saúde. Resolução 196 de 10 de outubro de 1996. Diretrizes e normas regulamentadoras de pesquisa envolvendo seres humanos. Diário Oficial da União 1996; 16 out.

21. Demazière D, Dubar C. Analyser les entretiens biographiques, l'exemple de récits d'insertion. Paris: Nathan; 1997. (Coll. Essais \& recherches)

22. Barthes R. Introdução à análise Estrutural da narrativa. In: Barthes R. A aventura semiológica. São Paulo: Martins Fontes; 2001. p. 163-202.

23. Rotenberg S, De Vargas S. Práticas alimentares e o cuidado da saúde: da alimentação da criança à alimentação da família. Rev. Bras Saúde Matern Infant 2004; $4(1): 85-94$.

24. Valente F. Em busca de uma educação nutricional crítica. In: Valente F. Fome e desnutrição: determinantes sociais. São Paulo: Cortez; 1986.

25. Giard L. Artes de nutrir. In: Certeau M, organizador. A invenção do cotidiano: morar, cozinhar. Rio de Janeiro: Vozes; 1998. p. 211-233

26. World Health Organization (WHO). Global status report on non communicable diseases 2010. Geneva: WHO; 2011.

27. Casemiro JP, Fonseca ABC, Secco FVM. Promover saúde na escola: reflexões a partir de uma revisão sobre saúde escolar na América Latina. Cien Saude Colet 2014; 19(3):829-840.

28. Czeresnia D. The concept of health and the difference between prevention and promotion. Cad Saude Publica 1999; 15(4):701-709.

29. Condrau F. The Patient's View Meets the Clinical Gaze. Social History of Medicine 2007; 20(3):525-540.

30. Buss PM. Promoção da saúde e qualidade de vida. Cien Saude Colet 2000; 5(1):163-177.

31. Viegas SMF. A Integralidade no cotidiano da Estratégia Saúde da Família nos Municípios do Vale do Jequitinhonha - Minas Gerais [tese]. Belo Horizonte: Universidade Federal de Minas Gerais; 2010.
32. Canguilhem G. O normal e o patológico. 7a ed. Rio de Janeiro: Forense Universitária; 2011.

33. Laplantine F. Antropologia da doença. $4^{a}$ ed. São Paulo: Martins Fontes, Coleção biblioteca universal; 2010.

34. Merhy EE, Franco TB. A produção imaginária da demanda e o processo de trabalho em saúde. In: Pinheiro R, Mattos RA, organizadores. Construção social da demanda: direito à saúde, trabalho em equipe, participação e espaços públicos. Rio de Janeiro: CEPESC/UERJ, Abrasco; 2005. p. 181-193.

35. Viegas SMF, Penna CMM. O vínculo como diretriz para a construção da integralidade na Estratégia Saúde da Família. Rev Rene 2012; 13(2):375-385.

36. Verdi M, Caponi S. Reflexões sobre a Promoção da Saúde numa perspectiva bioética. Texto Contexto Enferm 2005; 14(1):82-88.

37. Carvalho SR, Gastaldo D. Promoção à saúde e empoderamento: uma reflexão a partir das perspectivas crítico-social pós-estruturalista. Cien saude colet 2008; 13(Supl. 2):2029-2040.

38. Grmek M. O enigma do aparecimento da Aids. Estud. av. 1995; 9(24):229-239.

39. Oliveira MAC, Egry EY. A historicidade das teorias interpretativas do processo saúde-doença. Rev. Esc. Enferm. USP 2000; 34(1):9-15.

Article submitted on 09/24/2014

Accepted for publication on 10/31/2014

Final version submitted on $11 / 02 / 2014$ 